\title{
Renal function and clinical outcome of patients with cancer-associated venous thromboembolism randomized to receive apixaban or dalteparin. Results from the Caravaggio trial
}

Cecilia Becattini, ${ }^{1}$ Rupert Bauersachs, ${ }^{2}$ Giorgio Maraziti, ${ }^{1}$ Laurent Bertoletti, ${ }^{3}$ Alexander Cohen, ${ }^{4}$ Jean M. Connors, ${ }^{5}$ Dario Manfellotto, ${ }^{6}$ Antonio Sanchez, ${ }^{7}$ Benjamin Brenner ${ }^{8}$ and Giancarlo Agnelli ${ }^{1}$

IInternal, Vascular and Emergency Medicine - Stroke Unit, University of Perugia, Perugia, Italy; ${ }^{2}$ Klinikum Darmstadt GmbH, Darmstadt, Germany; ${ }^{3}$ Service de Médecine Vasculaire et Thérapeutique, CHU de St-Etienne, Saint-Etienne, France; ${ }^{4}$ Department of Haematology, St. Thomas' Hospital, King's College London, London, UK; ${ }^{5}$ Brigham and Women's

Hospital/Hematology Division, Harvard Medical School, Boston, MA, USA; ${ }^{6}$ Clinical Research Department, FADOI Foundation, Milan, Italy; ${ }^{6}$ Internal Medicine Department, Fatebenefratelli Foundation, San Giovanni Calibita Fatebenefratelli Hospital, Rome, Italy; ${ }^{7}$ Hospital Puerta de Hierro, Madrid, Spain and ${ }^{8}$ Institute of Hematology and BMT Rambam Health Care Campus Technion, Israel Institute of Technology Haifa, Haifa, Israel

\author{
Correspondence: \\ Cecilia Becattini \\ cecilia.becattini@unipg.it \\ Received: $\quad$ April 29, 2021 \\ Accepted: July 30, 2021 \\ Prepublished: $\quad$ August 12, 2021 \\ https://doi.org/10.3324/haematol.2021.279072 \\ ๑2022 Ferrata Storti Foundation \\ Haematologica material is published under a CC \\ BY-NC license @ (ब)
}

\begin{abstract}
The effect of renal impairment (RI) on risk of bleeding and recurrent thrombosis in cancer patients treated with direct oral anticoagulants for venous thromboembolism (VTE) is undefined. We ran a prespecified analysis of the randomized Caravaggio study to evaluate the role of $\mathrm{RI}$ as a risk factor for bleeding or recurrence in patients treated with dalteparin or apixaban for cancerassociated VTE. RI was graded as moderate (creatinine clearance between 30-59 mL/minute; 275 patients) and mild (between 60$89 \mathrm{~mL} /$ minute; 444 patients). In the 1142 patients included in this analysis, the incidence of major bleeding was similar in patients with moderate vs. no or mild RI (HR 1.06-95\% Cl: 0.53-2.11), with no difference in the relative safety of apixaban and dalteparin. Recurrent VTE was not different in moderate vs. no or mild RI (HR=0.67, 95\% Cl: 0.38-1.20); in moderate RI, apixaban reduced recurrent VTE compared to dalteparin ( $\mathrm{HR}=0.27$, 95\% $\mathrm{Cl}$ : 0.08-0.96; P for interaction 0.1085). At multivariate analysis, no association was found between variation of renal function over time and major bleeding or recurrent VTE. Advanced or metastatic cancer was the only independent predictor of major bleeding ( $\mathrm{HR}=2.84,95 \% \mathrm{Cl}$ : 1.20-6.71), with no effect of treatment with apixaban or dalteparin. In our study, in cancer patients treated with apixaban or dalteparin, moderate RI was not associated with major bleeding or recurrent VTE. In patients with moderate renal failure, the safety profile of apixaban was confirmed with the potential for improved efficacy in comparison to dalteparin. ClinicalTrials.gov identifier: NCT03045406.
\end{abstract}

\section{Introduction}

The treatment of venous thromboembolism (VTE) in cancer patients is challenging due to the high risk of recurrent VTE and bleeding. ${ }^{1,2}$ In these patients, low molecular weight heparin (LMWH) was shown to reduce the rate of recurrent VTE in comparison to vitamin $\mathrm{K}$ antagonists, without increasing bleeding complications.,4 Randomized studies have shown that the direct oral anti-Xa agents edoxaban, rivaroxaban and apixaban are non-inferior to dalteparin in the treatment of VTE in cancer patients. ${ }^{5-8}$ Hence, major international guidelines have recently considered direct oral anti-Xa agents as an alternative to $\mathrm{LMWH}$ for the treatment of cancer-associated VTE. ${ }^{9-11}$
Renal impairment ( $\mathrm{RI}$ ) was independently associated with an increase of approximately $40 \%$ in the risk of major bleeding (4.6 vs. 2.4\% person-years, adjusted hazard ratio $=1.40 ; 95 \% \mathrm{Cl}: 1.03-1.90)$ and recurrent thromboembolism (6.6 vs. 5.0\% person-years, adjusted hazard ratio= 1.40; 95\% Cl: 1.10-1.77) in patients receiving anticoagulants for the treatment of VTE. ${ }^{12}$ The association between RI and the risk for recurrent VTE and bleeding was assessed in cancer patients receiving LMWH or vitamin $\mathrm{K}$ antagonists in observational studies and in sub-analyses of randomized studies. ${ }^{13-16}$ In these sub-analyses, the efficacy to safety profile of LMWH in comparison to warfarin was similar in cancer patients with and without RI.13-16 The effect of RI on the risk of recurrent VTE and bleeding 
in patients with cancer-associated VTE treated with direct oral anti-Xa agents is uncertain..$^{17}$ As direct anti-Xa agents have a variable but substantial degree of renal excretion, RI may be associated with increased plasma levels of these agents with potential for increased bleeding risk. In phase III randomized controlled trials of direct oral anticoagulants for the treatment of VTE in the general population, no difference in recurrent VTE (RR $=0.70,95 \% \mathrm{Cl}$ : $0.43-1.15)$ but a significant reduction in major bleeding $(\mathrm{RR}=0.51,95 \% \mathrm{Cl}: 0.26-0.99)$ was seen in comparison with vitamin $\mathrm{K}$ antagonists in patients with creatinine clearance of $30-49 \mathrm{~mL} / \mathrm{min}^{18}$

The effect of RI on the efficacy and safety profile of the direct oral anticoagulants in the four randomized clinical studies of oral anti-Xa agents in patients with cancer associated VTE is unknown. In these studies, although patients with a creatinine clearance $<30 \mathrm{~mL} / \mathrm{min}$ were excluded, a consistent proportion of patients had mild or moderate RI. ${ }^{5-8}$

In the Caravaggio study, oral apixaban was found to be non-inferior to subcutaneous dalteparin for the treatment of cancer-associated VTE., ${ }^{8,19}$ The rate of major bleeding was similar with apixaban and dalteparin. The aim of this pre-specified analysis in patients included in the Caravaggio study was to assess the association between RI and bleeding or recurrent VTE. The effect of both baseline renal function and its variations during treatment with apixaban or dalteparin was evaluated for the association with major bleeding and recurrent VTE.

\section{Methods}

Caravaggio was a multinational, prospective, randomized, open-label, with blinded end-point evaluation (PROBE), non-inferiority study aimed at assessing whether oral apixaban was non-inferior to dalteparin for the treatment of newly diagnosed proximal deep vein thrombosis (DVT) and/or pulmonary embolism (PE) in patients with cancer. The rationale, design and results of the Caravaggio study were described previously. ${ }^{8,19}$

The trial was performed in accordance with the provisions of the Declaration of Helsinki and local regulations. The protocol and its amendments were approved by the institutional review board or ethics committee at each trial center. All the patients provided written informed consent.

Consecutive adult patients with cancer who had symptomatic or incidental acute proximal DVT or PE were randomized to receive oral apixaban (10 $\mathrm{mg}$ twice daily for the first 7 days, followed by $5 \mathrm{mg}$ twice daily) or subcutaneous dalteparin (200 IU per kilogram of body weight once daily for the first month, followed by $150 \mathrm{IU}$ per kilogram once daily) for 6 months. Inclusion and exclusion
Table 1. Renal impairment stage classification.

\begin{tabular}{|l|c|c|}
\hline RI stage & $\begin{array}{c}\text { Severity } \\
\text { classification }\end{array}$ & eGFR* \\
\hline I & Preserved & $\geq 90 \mathrm{~mL} / \mathrm{min}$ \\
\hline II & Mild reduction & $<90 \mathrm{~mL} / \mathrm{min}$ and $\geq 60 \mathrm{~mL} / \mathrm{min}$ \\
\hline III & Moderate reduction & $<60 \mathrm{~mL} / \mathrm{min}$ and $\geq 30 \mathrm{~mL} / \mathrm{min}$ \\
III & - & $<60 \mathrm{~mL} / \mathrm{min}$ and $\geq 45 \mathrm{~mL} / \mathrm{min}$ \\
IIIb & - & $<45 \mathrm{~mL} / \mathrm{min}$ and $\geq 30 \mathrm{~mL} / \mathrm{min}$ \\
\hline IV & Severe reduction & $<30 \mathrm{~mL} / \mathrm{min}$ and $\geq 15 \mathrm{~mL} / \mathrm{min}$ \\
\hline V & Pre-dialysis & $<15 \mathrm{~mL} / \mathrm{min}$ \\
\hline
\end{tabular}

*eGFR based on the Cockcroft-Gault equation. RI: renal impairment; eGFR: estimated glomerular filtration rate.

criteria are reported in the Online Supplementary Data. Only patients with baseline creatinine assessment at randomization were included in this prespecified analysis. Patients were excluded in case of a creatinine clearance $<30 \mathrm{~mL} / \mathrm{min}$ based on the Cockcroft Gault equation. RI was classified into the conventional five stages as indicated in Table $1 .{ }^{20}$

\section{Study outcomes}

This analysis has two co-primary outcomes: major bleeding and recurrent VTE defined according to Caravaggio criteria and occurring from randomization to day 180 (see Online Supplementary Data).

Secondary study outcomes were clinically relevant nonmajor bleeding and a composite of major bleeding and recurrent VTE.

\section{Follow-up and measurements}

Renal function was calculated by three accepted methods, the Cockcroft-Gault, Chronic Kidney Disease Epidemiology Collaboration (CKD-EPI), and Modification of Diet in Renal Disease (MDRD) equations (see Online Supplementary Data). ${ }^{21-23}$

Patients were also categorized on the basis of estimated glomerular filtration rate (eGFR) as having no or mild RI (eGFR of $60 \mathrm{~mL} / \mathrm{min}$ or higher) vs. moderate RI (eGFR lower than $60 \mathrm{~mL} / \mathrm{min}$ ) and having eGFR of $\geq 50 \mathrm{~mL} / \mathrm{min}$ vs. $<50 \mathrm{~mL} / \mathrm{min}$. The management of study treatments according to creatinine clearance was dictated by the protocol.

\section{Statistical analysis}

To assess the effect of RI in the risk for study outcome events, two different analyses were performed:

(i) a comparison of event rates in subgroups of patients randomized to apixaban or dalteparin, identified based on a specific cut-off level for eGFR (60 or $50 \mathrm{~mL} / \mathrm{min}$ ) at inclusion in the study;

(ii) proportional hazards model for the time to study outcome events with eGFR (according to the Cockroft-Gault formula) as a time-varying covariate. We analysed log- 
Table 2. Baseline renal function in patients randomized to apixaban or dalteparin.

\begin{tabular}{|c|c|c|c|}
\hline & $\begin{array}{l}\text { All patients } \\
\mathrm{N}=1142(\%)\end{array}$ & $\begin{array}{c}\text { Apixaban } \\
\mathrm{N}=573(50.2 \%)\end{array}$ & $\begin{array}{c}\text { Dalteparin } \\
\mathrm{N}=569(49.8 \%)\end{array}$ \\
\hline \multicolumn{4}{|l|}{ Baseline eGFR } \\
\hline Cockroft-Gault, mean \pm SD & $85.2 \pm 33.9$ & $84.8 \pm 34.4$ & $85.6 \pm 33.5$ \\
\hline CKD-EPI, mean \pm SD & $78.3 \pm 20.8$ & $78.5 \pm 20.7$ & $78.1 \pm 20.8$ \\
\hline MDRD, mean \pm SD & $87.0 \pm 33.9$ & $86.7 \pm 32.3$ & $86.4 \pm 30.6$ \\
\hline \multicolumn{4}{|c|}{ CKD stage according to Cockroft-Gault formula, $\mathrm{n}(\%)$} \\
\hline I (eGFR $\geq 90 \mathrm{~mL} / \mathrm{min})$ & $423(37.0)$ & $201(35.1)$ & $222(39.0)$ \\
\hline II (eGFR <90 mL/min and $\geq 60 \mathrm{~mL} / \mathrm{min}$ ) & $444(38.9)$ & $235(41.0)$ & $209(36.7)$ \\
\hline Illa (eGFR $<60 \mathrm{~mL} / \mathrm{min}$ and $\geq 45 \mathrm{~mL} / \mathrm{min}$ ) & $181(15.8)$ & $97(16.9)$ & $84(14.8)$ \\
\hline IIlb (eGFR <45 mL/min and $\geq 30 \mathrm{~mL} / \mathrm{min}$ ) & $94(8.2)$ & $40(7.0)$ & $54(9.5)$ \\
\hline \multicolumn{4}{|l|}{ CKD stage according to CKD-EPI, n (\%) } \\
\hline I (eGFR $\geq 90 \mathrm{~mL} / \mathrm{min})$ & $364(31.9)$ & $176(30.7)$ & $188(33.0)$ \\
\hline II (eGFR <90 mL/min and $\geq 60 \mathrm{~mL} / \mathrm{min}$ ) & $524(45.9)$ & $270(47.1)$ & $254(44.6)$ \\
\hline IIla (eGFR $<60 \mathrm{~mL} / \mathrm{min}$ and $\geq 45 \mathrm{mLmin}$ ) & $189(16.5)$ & $97(16.9)$ & $92(16.2)$ \\
\hline Illb (eGFR $<45 \mathrm{~mL} / \mathrm{min}$ and $\geq 30 \mathrm{~mL} / \mathrm{min}$ ) & $62(5.4)$ & $29(5.1)$ & $33(5.8)$ \\
\hline IV (eGFR <30 mL/min and $\geq 15 \mathrm{~mL} / \mathrm{min})$ & $3(0.3)$ & $1(0.2)$ & $2(0.4)$ \\
\hline \multicolumn{4}{|l|}{ CKD stage according to MDRD, n (\%) } \\
\hline I (eGFR $\geq 90 \mathrm{~mL} / \mathrm{min})$ & $439(38.4)$ & $219(38.2)$ & $220(38.7)$ \\
\hline II (eGFR <90 mL/min and ₹60 mL/min) & $479(41.9)$ & $242(42.2)$ & $237(41.7)$ \\
\hline IIla (eGFR $<60 \mathrm{~mL} / \mathrm{min}$ and $\geq 45 \mathrm{mLmin}$ ) & $176(15.4)$ & $92(16.1)$ & $84(14.8)$ \\
\hline IIlb (eGFR $<45 \mathrm{~mL} / \mathrm{min}$ and $\geq 30 \mathrm{~mL} / \mathrm{min}$ ) & $46(4.0)$ & $19(3.3)$ & $27(4.7)$ \\
\hline IV (eGFR <30 mL/min and $\geq 15$ mL/min) & $2(0.2)$ & $1(0.2)$ & $1(0.2)$ \\
\hline
\end{tabular}

Percentages are calculated relative to the total number of subjects in the modified intention-to-treat analysis set in each group. eGFR: estimated glomerular filtration rate; SD: standard deviation; CKD-EPI: Chronic Kidney Disease Epidemiology Collaboration; MDRD: Modified Diet and Renal Disease.

transformed eGFR ( $\mathrm{Y}=\log (\mathrm{eGFR})$ data throughout, as previously described for this kind of analyses. ${ }^{24}$

The final set of covariates for the multivariate analysis was selected among those with a $P$-value of 0.15 or less at univariate analyses.

For comparison of proportions, deterioration of renal function was defined as a decrease in eGFR leading to a change of at least one stage from baseline values, according to the Cockroft-Gault formula. Because subgroup analyses in the present study were exploratory, the $P$ values were not adjusted for multiple comparisons and should be interpreted with caution.

Analyses were performed with SAS software (version 9.4). Other details are reported in the Online Supplementary Data.

\section{Results}

Overall, 1142 patients were included in this analysis (Online Supplementary Data, Table S1). Thirteen patients from the original Caravaggio study were excluded due to lack of renal function assessment at inclusion in the study - one of whom reported major bleeding during the study - or for an eGFR lower than $30 \mathrm{~mL} / \mathrm{min}$ at inclusion. Mean baseline eGFR according to the Cockroft-Gault, CKD-EPI and MDRD equations are reported in Table 2. At inclusion in the study, $37 \%$ of patients had stage 1, 39\% stage 2 and $24 \%$ stage $3 \mathrm{RI} ; 8.2 \%$ had stage $3 \mathrm{~b}$ RI with eGFR between 30 and $44 \mathrm{~mL} / \mathrm{min}$ according to the Cockroft-Gault formula. CKD-EPI classified a numerically lower proportion of patients in stage 1 and a numerically higher proportion in stage $2 \mathrm{RI}$ compared to Cockroft-Gault or MDRD equations. Mean baseline eGFR, as well as distribution across different stages of RI, were similar in patients randomized to apixaban or dalteparin whatever the formula used for calculation of eGFR (Table 2). At inclusion in the study, $23.9 \%$ and $24.3 \%$ of patients randomized to receive apixaban and dalteparin had stage $3 \mathrm{RI}$ according to the Cockroft-Gault formula, respectively.

The distribution of RI stage according to cancer stage or site is reported in Online Supplementary Data, Table S2.

\section{Renal function and study outcome events}

The mean eGFR at baseline was similar in patients who experienced a major bleeding event compared to patients who did not experience one during the study (Table 3). At inclusion in the study, $25 \%$ and $24 \%$ of patients who experienced or did not experience a major bleed during the study had stage $3 \mathrm{RI}$, respectively. Event rates by CKD stage calculated by different formulas are reported in Online Supplementary Data, Table S3.

The incidence of major bleeding was similar in patients with moderate RI vs. patients with no or mild RI (4.0 vs. 
Table 3. Baseline characteristics of the study population according to study outcome groups.

\begin{tabular}{|c|c|c|c|c|c|}
\hline & $\begin{array}{l}\text { All patients } \\
N=1142(\%)\end{array}$ & $\begin{array}{c}\text { Patients } \\
\text { with major } \\
\text { bleeding } \\
\mathrm{N}=44(3.9 \%)\end{array}$ & $\begin{array}{c}\text { Patients } \\
\text { without } \\
\text { major bleeding } \\
\mathbf{N}=1098 \\
(96.1 \%)\end{array}$ & $\begin{array}{l}\text { Patients with } \\
\text { recurrent VTE } \\
N=78(6.8 \%)\end{array}$ & $\begin{array}{c}\text { Patients } \\
\text { without } \\
\text { recurrent VTE } \\
\mathbf{N}=1064 \\
(93.2 \%)\end{array}$ \\
\hline \multicolumn{6}{|l|}{ Age, years } \\
\hline Mean \pm SD & $67.7 \pm 11.1$ & $67.9 \pm 8.2$ & $67.7 \pm 11.2$ & $65.5 \pm 10.2$ & $67.9 \pm 11.2$ \\
\hline > 75 years, $\mathrm{N}(\%)$ & $296(25.9)$ & $9(20.5)$ & $287(26.1)$ & $14(17.9)$ & $282(26.5)$ \\
\hline Range & 21-93 & $51-86$ & $21-93$ & $42-87$ & $21-93$ \\
\hline Female gender, $\mathrm{N}$ & 579 & 20 & 559 & 38 & 541 \\
\hline BMI, mean \pm SD & $26.7 \pm 5.2$ & $25.6 \pm 4.1$ & $26.8 \pm 5.2$ & $26.5 \pm 5.2$ & $26.8 \pm 5.2$ \\
\hline \multicolumn{6}{|l|}{ Baseline eGFR } \\
\hline Cockroft Gault, mean \pm SD & $85.2 \pm 33.9$ & $81.5 \pm 29.1$ & $85.4 \pm 34.1$ & $96.1 \pm 39.4$ & $84.4 \pm 33.4$ \\
\hline CKD-EPI, mean \pm SD & $78.3 \pm 20.8$ & $79.3 \pm 22.0$ & $78.2 \pm 20.7$ & $84.8 \pm 21.1$ & $77.8 \pm 20.7$ \\
\hline MDRD, mean \pm SD & $86.7 \pm 32.3$ & $89.2 \pm 36.6$ & $86.6 \pm 32.1$ & $98.4 \pm 50.2$ & $85.8 \pm 30.4$ \\
\hline \multicolumn{6}{|l|}{$\begin{array}{l}\text { CKD stage according to Cockroft-Gault } \\
\text { formula, } N(\%)\end{array}$} \\
\hline I (eGFR $\geq 90 \mathrm{~mL} / \mathrm{min})$ & $423(37.0)$ & $18(40.9)$ & $405(36.9)$ & $39(50.0)$ & $405(36.9)$ \\
\hline II (eGFR <90 mL/min and $\geq 60$ mL/min) & $444(38.9)$ & $15(34.1)$ & $429(39.1)$ & $25(32.1)$ & $429(39.1)$ \\
\hline IIla (eGFR $<60 \mathrm{~mL} / \mathrm{min}$ and $\geq 45 \mathrm{~mL} / \mathrm{min}$ ) & $181(15.8)$ & $6(13.6)$ & $175(15.9)$ & $10(12.8)$ & $175(15.9)$ \\
\hline IIlb (eGFR $<45 \mathrm{~mL} / \mathrm{min}$ and $\geq 30 \mathrm{~mL} / \mathrm{min})$ & $94(8.2)$ & $5(11.4)$ & $89(8.1)$ & $4(5.1)$ & $89(8.1)$ \\
\hline \multicolumn{6}{|l|}{ CKD stage according to CKD-EPI, N (\%) } \\
\hline I (eGFR $\geq 90 \mathrm{~mL} / \mathrm{min})$ & $364(31.9)$ & $15(34.1)$ & $349(31.8)$ & $32(41.0)$ & $332(31.2)$ \\
\hline II (eGFR <90 mL/min and $\geq 60 \mathrm{~mL} / \mathrm{min}$ ) & $524(45.9)$ & $18(40.9)$ & $506(46.1)$ & $32(41.0)$ & $492(46.2)$ \\
\hline IIla (eGFR $<60 \mathrm{~mL} / \mathrm{min}$ and $\geq 45 \mathrm{~mL} / \mathrm{min}$ ) & $189(16.5)$ & 8 (18.2) & $181(16.5)$ & $13(16.7)$ & $176(16.5)$ \\
\hline IIlb (eGFR $<45 \mathrm{~mL} / \mathrm{min}$ and $\geq 30 \mathrm{~mL} / \mathrm{min}$ ) & $62(5.4)$ & $2(4.5)$ & $60(5.5)$ & $1(1.3)$ & $61(5.7)$ \\
\hline IV (eGFR <30 mL/min and $\geq 15$ mL/min) & $3(0.3)$ & $1(2.3)$ & $2(0.2)$ & $0(0.0)$ & $3(0.3)$ \\
\hline \multicolumn{6}{|l|}{ CKD stage according to MDRD, $\mathrm{N}(\%)$} \\
\hline I (eGFR $\geq 90 \mathrm{~mL} / \mathrm{min})$ & $439(38.4)$ & $19(43.2)$ & $420(38.3)$ & $39(50.0)$ & $400(37.6)$ \\
\hline II (eGFR <90 mLmin and $\geq 60$ mL/min) & $479(41.9)$ & $15(34.1)$ & $464(42.3)$ & $29(37.2)$ & $450(42.3)$ \\
\hline Illa (eGFR $<60 \mathrm{~mL} / \mathrm{min}$ and $\geq 45 \mathrm{~mL} / \mathrm{min}$ ) & $176(15.4)$ & $8(18.2)$ & $168(15.3)$ & $10(12.8)$ & $166(15.6)$ \\
\hline Illb (eGFR $<45 \mathrm{~mL} / \mathrm{min}$ and $\geq 30 \mathrm{~mL} / \mathrm{min}$ ) & $46(4.0)$ & $1(2.3)$ & $45(4.1)$ & $0(0.0)$ & $46(4.3)$ \\
\hline IV (eGFR <30 mL/min and $\geq 15 \mathrm{~mL} / \mathrm{min})$ & $2(0.2)$ & $1(2.3)$ & $1(0.1)$ & $0(0.0)$ & $2(0.2)$ \\
\hline $\begin{array}{l}\text { Locally advanced or metastatic cancer, } \\
\mathrm{N}(\%)\end{array}$ & $779(68.2)$ & $38(85.4)$ & $741(67.5)$ & $38(85.4)$ & $741(67.5)$ \\
\hline \multicolumn{6}{|l|}{ ECOG score, $N(\%)$} \\
\hline 1 & $553(48.4)$ & $20(45.5)$ & $533(48.5)$ & $20(45.5)$ & $533(48.5)$ \\
\hline 2 & $235(20.6)$ & $14(31.8)$ & $221(20.1)$ & $14(31.8)$ & $221(20.1)$ \\
\hline
\end{tabular}

MB: major bleeding. *according to Cockroft-Gault formula. VTE: venous thromboembolism: SD: standard deviation; GFR: estimated glomerular filtration rate; CKD-EPI: Chronic Kidney Disease Epidemiology Collaboration; MDRD: Modified Diet and Renal Disease; CKD: chronic kidney disease; ECOG: Eastern Cooperative Oncology Group.

3.8\%; HR=1.06, 95\% Cl: 0.53-2.11) (Table 4). These results were confirmed in patients randomized to receive apixaban (3.6 vs. 3.7\%) or dalteparin (4.3 vs. 3.9\%). Rates of major bleeding were similar in patients randomized to apixaban or dalteparin in the two groups of moderate RI and no or mild RI ( $P$-value for interaction 0.8819). These results were confirmed in patients with eGFR below or above 50 $\mathrm{mL} / \mathrm{min}$.

A numerically lower rate of recurrent VTE was observed in patients with moderate RI as compared to patients with no or mild RI (HR=0.67, 95\% Cl: 0.38-1.20). Among patients randomized to apixaban, a not significant $69 \%$ reduction of recurrent VTE was observed in those with moderate RI compared to those with no or mild RI (2.2 vs. $6.7 \%$; HR= $0.31,95 \% \mathrm{Cl}: 0.09-1.03)$. No difference in recurrent VTE was observed with dalteparin in patients with moderate RI vs. no or mild RI. A lower incidence of recurrent VTE was observed in patients with moderate RI randomized to apixaban compared to dalteparin (2.2 vs. 8.0\%; HR=0.27, 95\% $\mathrm{Cl}$ : 0.08-0.96, $P$-value for interaction 0.1085$)$. The reduction of recurrent VTE with apixaban compared to dalteparin was confirmed in patients with eGFR lower than 50 $\mathrm{mL} / \mathrm{min}$.

A numerically higher rate of clinically relevant non-major 
Table 4. Frequency of study outcome events based on baseline estimated glomerular filtration rate calculated according to the Cockroft-Gault formula.

\begin{tabular}{|c|c|c|c|c|c|c|c|c|c|c|c|}
\hline & \multicolumn{3}{|c|}{ Major bleeding } & \multirow[t]{2}{*}{$\begin{array}{c}\text { HR } \\
(95 \% \mathrm{Cl})\end{array}$} & \multirow[t]{2}{*}{$\begin{array}{c}P \text { for } \\
\text { interaction }\end{array}$} & & \multicolumn{3}{|c|}{ Major bleeding } & \multirow[t]{2}{*}{$\begin{array}{c}\text { HR } \\
(95 \% \mathrm{CI})\end{array}$} & \multirow[t]{2}{*}{$\begin{array}{c}P \text { for } \\
\text { interaction }\end{array}$} \\
\hline & Overall & Apixaban & Dalteparin & & & & Overall & Apixaban & Dalteparin & & \\
\hline eGFR $<60^{*}$ & $11 / 275$ & $5 / 137$ & $6 / 138$ & $0 \cdot 84$ & $0 \cdot 8819$ & eGFR $<50^{*}$ & $7 / 150$ & $3 / 68$ & $4 / 82$ & 0.85 & 0.9757 \\
\hline$n / N, \%$ & 4.0 & 3.6 & 4.3 & $0.26-2.71$ & & $\mathrm{n} / \mathrm{N} \%$ & 4.7 & 4.4 & 4.9 & $0.19-3.80$ & \\
\hline eGFR $\geq 60^{*}$ & $33 / 867$ & $16 / 436$ & $17 / 431$ & 0.92 & & eGFR $\geq 50^{*}$ & $37 / 992$ & $18 / 505$ & $19 / 487$ & 0.91 & \\
\hline $\mathrm{n} / \mathrm{N}, \%$ & 3.8 & 3.7 & 3.9 & $0.47-1.83$ & & $\mathrm{n} / \mathrm{N}, \%$ & 3.7 & 3.6 & 3.9 & $0.48-1.73$ & \\
\hline HR & 1.06 & 1.02 & 1.11 & & & $\mathrm{HR}$ & 1.26 & 1.24 & 1.28 & & \\
\hline \multirow[t]{3}{*}{$95 \% \mathrm{Cl}$} & $0.53-2.11$ & $0.37-2.79$ & $0.43-2.83$ & & & $95 \% \mathrm{Cl}$ & $0.56-2.84$ & $0.37-4.20$ & $0.43-3.79$ & & \\
\hline & \multicolumn{3}{|c|}{ Recurrent VTE } & $\begin{array}{c}\text { HR } \\
(95 \% \mathrm{Cl})\end{array}$ & $\begin{array}{c}P \text { for } \\
\text { interaction }\end{array}$ & & \multicolumn{3}{|c|}{ Recurrent VTE } & $\begin{array}{c}\text { HR } \\
(95 \% \mathrm{Cl})\end{array}$ & $\begin{array}{c}P \text { for } \\
\text { interaction }\end{array}$ \\
\hline & Overall & Apixaban & Dalteparin & & & & Overall & Apixaban & Dalteparin & & \\
\hline eGFR $<60^{*}$ & $14 / 275$ & $3 / 137$ & $11 / 138$ & 0.27 & 0.1085 & eGFR $<50^{*}$ & $6 / 150$ & $0 / 68$ & $6 / 82$ & N.A. & N.A. \\
\hline$n / N, \%$ & 5.1 & 2.2 & 8.0 & $0.08-0.96$ & & $\mathrm{n} / \mathrm{N} \%$ & 4.0 & 0.0 & 7.3 & & \\
\hline eGFR $\geq 60^{*}$ & $64 / 867$ & $29 / 436$ & $35 / 431$ & 0.82 & & eGFR $\geq 50^{*}$ & $72 / 992$ & $32 / 505$ & $40 / 487$ & 0.76 & \\
\hline$n / N, \%$ & 7.4 & 6.7 & 8.1 & $0.50-1.33$ & & $\mathrm{n} / \mathrm{N}(\%)$ & 7.3 & 6.3 & 8.2 & $0.48-1.22$ & \\
\hline $\mathrm{HR}$ & 0.67 & 0.31 & 0.97 & & & $\mathrm{HR}$ & 0.53 & N.A. & 0.87 & & \\
\hline \multirow[t]{3}{*}{$95 \% \mathrm{Cl}$} & $0.38-1.20$ & $0.09-1.03$ & $0.50-1.91$ & & & $95 \% \mathrm{Cl}$ & $0.23-1.22$ & & $0.37-2.04$ & & \\
\hline & \multicolumn{3}{|c|}{$\begin{array}{l}\text { Recurrent VTE or } \\
\text { major bleeding }\end{array}$} & $\begin{array}{c}\text { HR } \\
95 \% \mathrm{Cl}\end{array}$ & $\begin{array}{c}P \text { for } \\
\text { interaction }\end{array}$ & & \multicolumn{3}{|c|}{$\begin{array}{l}\text { Recurrent VTE or } \\
\text { major bleeding }\end{array}$} & $\begin{array}{c}\text { HR } \\
(95 \% \mathrm{Cl})\end{array}$ & $\begin{array}{c}P \text { for } \\
\text { interaction }\end{array}$ \\
\hline & Overall & Apixaban & Dalteparin & & & & Overall & Apixaban & Dalteparin & & \\
\hline eGFR $<60^{*}$ & $23 / 275$ & $8 / 137$ & $15 / 138$ & 0.53 & $0 \cdot 3675$ & eGFR $<50^{*}$ & $12 / 150$ & $3 / 68$ & $9 / 82$ & 0.39 & 0.2947 \\
\hline$n / N, \%$ & 8.4 & 5.8 & 15/138 10.9 & $0.23-1.24$ & & $\mathrm{n} / \mathrm{N} \%$ & 8.0 & 4.4 & 11.0 & $0.12-1.40$ & \\
\hline eGFR $\geq 60^{*}$ & $93 / 867$ & $42 / 436$ & $51 / 431$ & 0.81 & & eGFR $\geq 50^{*}$ & 104/992 & $47 / 505$ & $57 / 487$ & 0.78 & \\
\hline$n / N, \%$ & 10.7 & 9.6 & 11.8 & $0.54-1.21$ & & $\mathrm{n} / \mathrm{N} \%$ & 10.5 & 9.3 & 11.7 & $0.53-1.15$ & \\
\hline HR & 0.76 & 0.59 & 0.91 & & & $\mathrm{HR}$ & 0.74 & 0.45 & 0.92 & & \\
\hline \multirow[t]{3}{*}{$95 \% \mathrm{Cl}$} & $0.48-1.21$ & $0.27-1.26$ & $0.51-1.61$ & & & $95 \% \mathrm{Cl}$ & $0.41-1.34$ & $0.14-1.46$ & $0.46-1.86$ & & \\
\hline & \multicolumn{3}{|c|}{$\begin{array}{l}\text { Clinically relevant } \\
\text { non-major bleeding }\end{array}$} & $\begin{array}{c}\text { HR } \\
(95 \% \mathrm{Cl})\end{array}$ & $\begin{array}{c}P \text { for } \\
\text { interaction }\end{array}$ & & \multicolumn{3}{|c|}{$\begin{array}{l}\text { Clinically relevant } \\
\text { non-major bleeding }\end{array}$} & $\begin{array}{c}\text { HR } \\
(95 \% \mathrm{Cl})\end{array}$ & $\begin{array}{c}P \text { for } \\
\text { interaction }\end{array}$ \\
\hline & Overall & Apixaban & Dalteparin & & & & Overall & Apixaban & Dalteparin & & \\
\hline eGFR $<60^{*}$ & $26 / 275$ & $18 / 137$ & $8 / 138$ & 2.35 & 0.2364 & eGFR $<50^{*}$ & $12 / 150$ & $5 / 68$ & $7 / 82$ & 0.87 & 0.2682 \\
\hline $\mathrm{n} / \mathrm{N}, \%$ & 9.5 & 13.1 & 5.8 & $1.01-5.45$ & & $\mathrm{n} / \mathrm{N}, \%$ & 8.0 & 7.4 & 8.5 & $0.27-2.76$ & \\
\hline eGFR $\geq 60^{*}$ & $61 / 867$ & $34 / 436$ & $27 / 431$ & 1.26 & & eGFR $\geq 50^{*}$ & $75 / 992$ & $47 / 505$ & $28 / 487$ & 1.65 & \\
\hline $\mathrm{n} / \mathrm{N}, \%$ & 7.0 & 7.8 & 6.3 & $0.76-2.09$ & & $\mathrm{n} / \mathrm{N}, \%$ & 7.6 & 9.3 & 5.7 & $1.03-2.63$ & \\
\hline $\mathrm{HR}$ & 1.35 & 1.67 & 0.94 & & & $\mathrm{HR}$ & 1.05 & 0.76 & 1.53 & & \\
\hline \multirow[t]{3}{*}{$(95 \% \mathrm{Cl})$} & $0.85-2.12$ & $0.95-2.94$ & $0.42-2.08$ & & & $(95 \% \mathrm{Cl})$ & $0.57-1.93$ & $0.31-1.90$ & $0.66-3.56$ & & \\
\hline & \multicolumn{3}{|c|}{ Major bleeding or CRNMB } & $\begin{array}{c}\text { HR } \\
(95 \% \mathrm{Cl})\end{array}$ & $\begin{array}{c}P \text { for } \\
\text { interaction }\end{array}$ & & \multicolumn{3}{|c|}{ Major bleeding or CRNMB } & $\begin{array}{c}\text { HR } \\
(95 \% \mathrm{Cl})\end{array}$ & $\begin{array}{c}P \text { for } \\
\text { interaction }\end{array}$ \\
\hline & Overall & Apixaban & Dalteparin & & & & Overall & Apixaban & Dalteparin & & \\
\hline eGFR $<60^{*}$ & $36 / 275$ & $23 / 137$ & $13 / 138$ & 1.83 & 0.2011 & eGFR $<50^{*}$ & $18 / 150$ & $8 / 68$ & $10 / 82$ & 0.96 & 0.5026 \\
\hline$n / N, \%$ & 13.1 & 16.8 & 9.4 & $0.92-3.62$ & & $\mathrm{n} / \mathrm{N}, \%$ & 12.0 & 11.8 & 12.2 & $0.38-2.40$ & \\
\hline
\end{tabular}




\begin{tabular}{|l|c|c|c|c|c|c|c|c|c|}
\hline eGFR $\geq 60^{*}$ & $89 / 867$ & $46 / 436$ & $43 / 431$ & 1.06 & & eGFR $\geq 50^{*}$ & $107 / 992$ & $61 / 505$ & $46 / 487$ \\
\hline $\mathrm{n} / \mathrm{N}, \%$ & 10.3 & 10.6 & 10.0 & $0.70-1.61$ & & $\mathrm{n} / \mathrm{N}, \%$ & 10.8 & 12.1 & 9.4 \\
\hline $\mathrm{HR}$ & 1.28 & 1.61 & 0.95 & & & $\mathrm{HR}$ & 1.11 & 0.95 & 1.34 \\
\hline $95 \% \mathrm{Cl}$ & $0.87-1.89$ & $0.98-2.64$ & $0.51-1.78$ & & & $95 \% \mathrm{Cl}$ & $0.67-1.84$ & $0.46-1.98$ & \\
\hline
\end{tabular}

All patients in the modified intention-to-treat set with an available baseline value of estimated glomerular filtration rate (eGFR) are considered in this table. An eGFR cut-off of $50 \mathrm{~mL}$ per minute was used in some phase III studies with direct oral anticoagulants. The hazard ratios (HR) (last column of the table) are adjusted for the competing risk of death unrelated to event by resorting to the Fine \& Gray regression model using eGFR group, symptomatic vs. unsuspected VTE and active cancer vs. history of cancer as covariates. The HR for comparison between dalteparin and apixaban are adjusted for the competing risk of death unrelated to event by resorting to the Fine \& Gray regression model using treatment group, symptomatic vs. unsuspected venous thromboembolism and active cancer vs. history of cancer as covariates. n: number of patients with events; N: total number of patients in each category. HR: hazard ratio; 95\% CI: 95\% confidence interval; eGFR: estimated glomerular filtration rate; VTE: venous thromboembolism; CRNMB: clinically relevant non-major bleeding.

bleeding was observed in patients with moderate RI vs. no or mild RI, and this was mainly accounted for by patients randomized to receive apixaban (Table 4). In patients with moderate RI, a two-fold increase in the incidence of clinically relevant non-major bleeding was observed with apixaban in comparison to dalteparin $(P$ value for interaction 0.2364 ). Both major and clinically relevant non-major bleeding were more common at genito-urinary sites in patients with reduced eGFR (either lower than 60 or $50 \mathrm{~mL} / \mathrm{min}$ ) in comparison to patients with no or mild RI; both major and clinically relevant nonmajor bleeding were more common at gastrointestinal sites in patients with no or mild RI (eGFR higher than 60 or $50 \mathrm{~mL} / \mathrm{min}$ ) in comparison to patients with reduced eGFR (either lower than 60 or $50 \mathrm{~mL} / \mathrm{min}$ ) (Online Supplementary Data, Table S4).

\section{Renal function over time and study outcome}

During the six-month treatment period, 288 patients (25\%) experienced a deterioration of eGFR leading to a change of at least one stage from baseline values. This deterioration occurred in similar proportions of patients, regardless of the baseline eGFR stage (Online Supplementary Data, Table S5). Age at inclusion was associated with a deterioration of eGFR over time; treatment for cancer at inclusion or within the previous 6 months was associated with increasing eGFR over time (Online Supplementary Data, Table S6). No association was found between ECOG or cancer that was locally advanced/metastatic or unsuspected vs. symptomatic VTE or active cancer vs. history of cancer and eGFR over time. Variation of renal function over time was similar in patients randomized to receive apixaban or dalteparin (Online Supplementary Data, Figure S1).

A major bleed occurred in 2.8 and $4.2 \%$ of patients having and not having deterioration of eGFR leading to a change of at least one stage from baseline values, respectively (Online Supplementary Data, Table S7). Recurrent VTE occurred in $2.8 \%$ and $8.2 \%$ of patients with or without deterioration of eGFR leading to a change of at least one stage from baseline values, respectively.
Multivariate analyses using renal function as a time-varying covariate and with death unrelated to an event as a competing risk were performed for study outcome events. Recurrent or locally-advanced or metastatic cancer ( $H R=$ 2.84, 95\% Cl: 1.20-6.71) was an independent predictor of major bleeding (Table 5). No independent association was found between variation of renal function over time and major bleeding or recurrent VTE. A not significant association was found between recurrent or locally-advanced or metastatic cancer ( $\mathrm{HR}=1.65,95 \% \mathrm{Cl}: 0.95-2.86)$ or treatment with apixaban ( $\mathrm{HR}=0.66,95 \% \mathrm{Cl}: 0.42-1.05)$ and recurrent VTE. No association between variation of renal function over time and the risk for recurrent VTE was observed.

\section{Discussion}

Renal insufficiency occurs frequently in patients with cancer-associated VTE, with more than $60 \%$ of patients enrolled in the Caravaggio study having mild or moderate RI. RI was found not to be a risk factor for major bleeding or recurrent VTE in this population. No association was found between either moderate RI (eGFR lower than 60 $\mathrm{mL} / \mathrm{min}$ ) or defined by eGFR lower than $50 \mathrm{~mL} / \mathrm{min}$ and major bleeding in patients randomized to apixaban or dalteparin. Apixaban appeared to reduce recurrent VTE in patients with moderate RI in comparison to dalteparin, with no effect on the incidence of major bleeding but a not significant increase in clinically relevant non-major bleeding. The efficacy to safety ratio of apixaban was similar to that of dalteparin in patients with normal renal function or mild RI. Recurrent or locally advanced or metastatic cancer was the only independent predictor for major bleeding in this population of patients with cancer-associated VTE.

$\mathrm{RI}$ is a common condition in the general adult population and is prevalent in patients with cancer. In a single-center cohort study, about two-thirds of patients with solid cancer had abnormal renal function (eGFR $<90$ $\left.\mathrm{mL} / \mathrm{min} / 1.73 \mathrm{~m}^{2}\right) ; 15 \%$ had moderate $\mathrm{RI}$ and $1 \%$ to $2 \%$ had severe RI. ${ }^{25}$ In the CLOT study, $24 \%$ of patients with 
Table 5. Risk factors for major bleeding, recurrent venous thromboembolism or clinically relevant non-major bleeding according to a Cox model with time-varying covariates.

\begin{tabular}{|c|c|c|c|}
\hline & HR & $95 \% \mathrm{Cl}$ & $\boldsymbol{P}$ \\
\hline \multicolumn{4}{|l|}{ Risk factors for major bleeding } \\
\hline eGFR* over time & 0.57 & $0.21-1.55$ & 0.26 \\
\hline Baseline age (years) & 0.99 & 0.97-1.01 & 0.41 \\
\hline $\begin{array}{l}\text { Treatment for cancer at the time of inclusion or } \\
\text { within previous } 6 \text { months }\end{array}$ & 1.45 & $0.67-3.14$ & 0.35 \\
\hline Recurrent locally advanced or metastatic cancer & 2.84 & $1.20-6.71$ & 0.02 \\
\hline Treatment (reference Dalteparin) / Apixaban & 0.96 & $0.53-1.75$ & 0.89 \\
\hline \multicolumn{4}{|l|}{ Risk factors for recurrent VTE } \\
\hline eGFR* over time & 1.70 & $0.82-3.52$ & 0.15 \\
\hline Baseline age (years) & 0.99 & 0.97-1.01 & 0.48 \\
\hline $\begin{array}{l}\text { Treatment for cancer at the time of inclusion or } \\
\text { within previous } 6 \text { months }\end{array}$ & 0.74 & $0.33-1.62$ & 0.45 \\
\hline Recurrent locally advanced or metastatic cancer & 1.65 & $0.95-2.86$ & 0.08 \\
\hline Treatment (reference Dalteparin) / Apixaban & 0.66 & $0.42-1.05$ & 0.08 \\
\hline \multicolumn{4}{|l|}{$\begin{array}{l}\text { Risk factors for clinically relevant non-major } \\
\text { bleeding }\end{array}$} \\
\hline eGFR* over time & 1.18 & $0.61-2.28$ & 0.63 \\
\hline Baseline age (years) & 1.03 & $1.00-1.05$ & 0.03 \\
\hline $\begin{array}{l}\text { Treatment for cancer at the time of inclusion or } \\
\text { within previous } 6 \text { months }\end{array}$ & 1.07 & $0.59-1.98$ & 0.83 \\
\hline Recurrent locally advanced or metastatic cancer & 1.25 & $0.77-2.03$ & 0.36 \\
\hline Treatment (reference Dalteparin) / Apixaban & 1.52 & $0.99-2.35$ & 0.08 \\
\hline \multicolumn{4}{|l|}{ Risk factors for major bleeding or recurrent VTE } \\
\hline eGFR ${ }^{\star}$ over time & 1.17 & $0.62-2.22$ & 0.63 \\
\hline Baseline age (years) & 0.99 & $0.97-1.01$ & 0.23 \\
\hline $\begin{array}{l}\text { Treatment for cancer at the time of inclusion or } \\
\text { within previous } 6 \text { months }\end{array}$ & 1.08 & $0.62-1.86$ & 0.80 \\
\hline Recurrent locally advanced or metastatic cancer & 1.99 & $1.24-3.21$ & 0.004 \\
\hline Treatment (reference Dalteparin) / Apixaban & 0.74 & $0.51-1.07$ & 0.11 \\
\hline
\end{tabular}

All patients in the modified intention-to-treat set with an available baseline value of estimated glomerular filtration rate (eGFR) are considered in this table. *eGFR included in the analyses as log-transformed eGFR (see methods section). HR: hazard ratio; 95\% Cl: $95 \%$ confidence interval; VTE: venous thromboembolism.

cancer-associated VTE had eGFR lower than $60 \mathrm{~mL} / \mathrm{min}$, with $22 \%$ having moderate $\mathrm{RI}$ and $2 \%$ severe $\mathrm{RI} .^{16}$ In the Catch study, $15 \%$ of patients with cancer-associated VTE had eGFR lower than $60 \mathrm{~mL} / \mathrm{min}$ at inclusion; $15 \mathrm{RI}$ was more common in patients with gynecological and genitourinary malignancies. In the EINSTEIN VTE studies, more than half of the patients identified as having cancer had creatinine clearance $<80 \mathrm{~mL} / \mathrm{min}$ and $15 \%$ had creatinine clearance $<50 \mathrm{~mL} / \mathrm{min} .{ }^{26}$ In the Amplify VTE study, patients with active cancer or history of cancer more commonly had creatinine clearance lower than $50 \mathrm{~mL} / \mathrm{min}$ in comparison to non-cancer patients. ${ }^{27}$ Overall, our results showing a prevalence of moderate RI greater than $20 \%$ in patients with cancer-associated VTE are consistent with those from previous studies in this setting. The clinical relevance of our observation is related to the hypothesis that $\mathrm{RI}$ could reduce renal excretion of both $\mathrm{LMWH}$ and direct anti-Xa anticoagulants and potentially lead to anticoagulant overdosing and an increase in bleeding complications. Whether dose reduction or dose adjustment of LMWH based on anti-Xa activity are valid options to avoid an in- crease in bleeding risk in patients with severe $\mathrm{RI}$ is uncertain. ${ }^{28,29}$ The evidence in favor of these approaches is limited both in the general population of patients with VTE and in cancer patients with VTE. To date, the optimal anticoagulant agent and regimen in patients with severe renal failure is undefined. Among $L M W H$, dalteparin seems to be associated with acceptable bleeding risk in patients with RI. 16,30,31 Among direct oral anti-Xa anticoagulants, dose reduction for patients with $\mathrm{RI}$ was evaluated for edoxaban in the treatment of VTE. No dose adjustment has been tested in clinical trials for the treatment of VTE with apixaban or rivaroxaban. Our study shows that the current regimen of apixaban developed and approved for the treatment of VTE is effective and safe in cancer patients with moderate RI.

We found no association between RI and bleeding or thromboembolic risk in patients with cancer-associated VTE randomized to receive apixaban or dalteparin. These findings are in contrast with those from previous studies in the general population of patients with acute VTE as well as in cancer patients included in a randomized study 
that compared tinzaparin or dalteparin with warfarin..$^{12,15,16}$ These studies showed an increased risk of bleeding in patients with moderate $\mathrm{RI}$ in comparison with patients with no or mild RI. In two of these studies, RI was also associated with an increase in recurrent VTE. ${ }^{12,15} \mathrm{~A}$ comparison of recent studies with anti-Xa agents for the treatment of cancer-associated VTE is difficult as only about $7 \%$ of patients in the HOKUSAI VTE cancer study had moderate RI, with no RI data available for the Select-D study. ${ }^{5,6}$

This analysis shows similar safety profiles of apixaban and dalteparin across different stages of RI in terms of major bleeding. An increase in clinically relevant non-major bleeding was observed with apixaban compared to dalteparin in patients with moderate RI. This difference was mainly driven by an increase in apixaban-associated genito-urinary bleeding in patients with moderate RI. An increase in genito-urinary bleeding was reported in the main Caravaggio study and we have now added information that it is related to moderate RI. ${ }^{8}$ Whether this increase in genito-urinary bleeding is to be related to the presence of genito-urinary cancer, to the accumulation of study drugs at the urinary site or, rather, to the use of specific anticancer agents remains undefined. ${ }^{32}$ Indeed, as these findings derive from subgroup analyses and refer to limited numbers of events, they can only be regarded as hypothesis generating. In phase III trials with direct oral anticoagulants for the treatment of VTE, no effect of RI on efficacy was reported. ${ }^{1718}$ Concerning the safety of direct oral anticoagulants, the favorable effect observed in the general population was confirmed across different stages of RI.

In our study in patients with cancer-associated VTE, about $25 \%$ of patients had a significant variation of renal function leading to change in eGFR stage. A previous study in patients with cancer-associated VTE reported similar rates of variation of renal function over time..$^{15}$ Anticancer agents, particularly platinum-based agents, may affect renal function, potentially leading to deterioration of RI. In this case, patients with $\mathrm{RI}$ may require surveillance for periodical reassessment of renal function and bleeding risk.

In a subgroup meta-analysis on 1789 patients without cancer with creatinine clearance between 30 and 49 $\mathrm{mL} / \mathrm{min}$ included in phase III trials in the treatment of VTE, no difference in terms of recurrent VTE $(R R=0.70,95 \% \mathrm{Cl}$ : $0.43-1.15)$ was reported in patients receiving direct oral anticoagulants vs. vitamin $\mathrm{K}$ antagonists (VKA); however, a significant reduction in major bleedings ( $R R=0.51,95 \%$ $\mathrm{Cl}$ : $0.26-0.99)$ was found..$^{18}$ Similarly, in the four randomized clinical studies with oral anti-Xa agents for the treatment of cancer-associated VTE, no effect of renal function emerged on the efficacy and safety profile of these agents. ${ }^{5-8}$ Taken together, these data suggest that the oral anti-Xa agents could be used in patients with cancer-associated VTE and creatinine clearance $30-49 \mathrm{~mL} / \mathrm{min}$. Pa- tients with a creatinine clearance $<30 \mathrm{~mL} / \mathrm{min}$ were excluded from phase III clinical trials on the treatment of cancer-associated VTE and no dose adjustment was scheduled for direct oral anticoagulants based on renal function in these patients, except for the studies with edoxaban. Data regarding safety and efficacy of direct oral anticoagulants in cancer patients with severe renal impairment are lacking. It is conceivable that, for patients with creatinine clearance $<30 \mathrm{~mL} / \mathrm{min}$, treatment with unfractionated heparin may be preferred or, as an alternative, vitamin $\mathrm{K}$ antagonists can still be still an option. Despite being based on limited evidence, dose- and perhaps anti-Xa activity-adjusted LMWH might be considered. ${ }^{28,29,33,34}$ Further evidence is needed to define the optimal anticoagulant strategy for these patients.

Several equations are currently in use to non-invasively estimate eGFR. eGFR is an accepted index of renal function, regardless of the formula used for the calculation. The Cockcroft-Gault equation is, at present, the most widely used in clinical practice and was employed in phase III clinical trials with direct oral anticoagulants to calculate eGFR and adjust the dose of the oral anti-Xa agents. For this reason, the Cockcroft-Gault equation is commonly used to adjust dosing of direct oral anticoagulants in patients with atrial fibrillation. However, as this formula may overestimate eGFR, the CKD-EPI equation was developed to more accurately estimate eGFR across all ranges of renal function and was tested in sub-analyses of studies with direct oral anticoagulants. ${ }^{35}$ Cockcroft-Gault, CKD-EPI and MDRD are all serum creatinine-based estimations of eGFR and depend on age and gender. Differences across equations emerged in our study between the Cockcroft-Gault and CKD-EPI equations concerning proportions of patients classified with stage I or stage II RI. The majority of reclassifications occurred in the group estimated as having normal renal function according to the Cockcroft-Gault equation. However, incidences of study outcome events in our study were similar in stages I and II RI, as calculated by different formulas.

Our study has some limits. In particular, 13 patients included in the Caravaggio study were excluded from this analysis due to the lack of baseline creatinine value at the time of inclusion or to the violation of the inclusion requirement necessitating creatinine clearance greater than $30 \mathrm{~mL} / \mathrm{min}$. The study was designed as an open-label randomized study. Investigators were aware of study treatment assignment and of creatinine clearance values over time. The management of study treatments according to creatinine clearance was dictated by the protocol, demonstrating that accurate management of anticoagulant treatment may avoid complications due to deterioration of renal function. Finally, our analysis cannot provide information on the efficacy and safety of apixaban and 
dalteparin in patients with severe RI (creatinine clearance lower than $30 \mathrm{~mL} / \mathrm{min}$ ), as these patients were excluded from the Caravaggio study. Our study benefits from its randomized design with prospective assessments of renal function in a large population of cancer patients and the blind adjudication of all the study outcome events by an independent committee.

In conclusion, this analysis shows that a substantial proportion of cancer patients have RI when diagnosed with VTE, or experience a deterioration of renal function in the 6-month period beyond the index VTE. However, no effect of renal function at the initiation of anticoagulant treatment or of variation of renal function during anticoagulant treatment is associated with the risk for major bleeding or recurrent VTE in patients randomized to receive apixaban or dalteparin. Recurrent or locally-advanced or metastatic cancer was shown to be the only independent predictor of major bleeding in cancer patients with VTE. Clinically relevant non-major bleeding seems to be more common in patients with moderate RI receiving apixaban in comparison to dalteparin.

\section{Disclosures}

CB reports personal fees from Bayer HealthCare, Bristol Myers Squibb, and Daiichi Sankyo, outside the submitted work. RB reports personal fees from Bristol-Myers-Squibb, Pfizer, Bayer Healthcare, and LEO, outside the submitted work. GM has nothing to disclose. $L B$ reports grants, personal fees and non-financial support from Bristol-Myers Squibb/Pfizer, grants and personal fees from Bayer, personal fees and non-financial support from Leo-Pharma, personal fees and non-financial support from Aspen, outside the submitted work. AC reports personal fees from AbbVie, Bayer AG and Boehringer Ingelheim, grants and personal fees from Bristol-Myers Squibb, and Daiichi-Sankyo Europe, personal fees from Exom and Janssen, grants and personal fees from Pfizer Limited and personal fees from Alexion Pharmaceuticals, outside the submitted work. JMC reports personal fees from Abbott, Bristol-Myers Squibb, Pfizer, Takeda, and Portola, outside the submitted work. DM has nothing to disclose. AS has nothing to disclose. Dr. Brenner reports personal fees from Bayer, ROVI Pharmaceuticals, Sanofi, and Leo Pharma, outside the submitted work. GA reports personal fees from Bristol-Myers-Squibb, Pfizer, and Bayer Healthcare, outside the submitted work.

\section{Contributions}

$C B, G M, R B$ and $G A$ were responsible for the conception and design of the study or analysis and interpretation of data, or both. All authors contributed to drafting the manuscript or revising it critically for important intellectual content and provided final approval of the manuscript submitted.

\section{Funding}

The Caravaggio study was funded by an unrestricted grant from the Bristol-Myers Squibb-Pfizer Alliance.

\section{Data-sharing statement}

Data collected for the study may be shared after approval of potential proposals by the Steering Committee and with a signed data-access agreement, and at least 6 months after manuscript publication.

\section{References}

1.Prandoni P, Lensing AWA, Piccioli A, et al. Recurrent venous thromboembolism and bleeding complications during anticoagulant treatment in patients with cancer and venous thrombosis. Blood. 2002;100(10):3484-3488.

2. Weitz JI, Haas S, Ageno W, et al. Cancer associated thrombosis in everyday practice: perspectives from GARFIELD-VTE. J Thromb Thrombolysis. 2020;50(2):267-277.

3.Lee AYY, Kamphuisen PW, Meyer G, et al. Tinzaparin vs warfarin for treatment of acute venous thromboembolism in patients with active cancer. JAMA. 2015;314(7):677-686.

4.Lee AYY, Levine MN, Baker RI, et al. Low-molecular-weight heparin versus a coumarin for the prevention of recurrent venous thromboembolism in patients with cancer. $\mathrm{N}$ Engl $\mathrm{J}$ Med 2003;349(2):146-153.

5.Raskob GE, van Es N, Verhamme P, et al. Edoxaban for the treatment of cancer-associated venous thromboembolism. N Engl J Med. 2018;378(7):615-624.

6. Young AM, Marshall A, Thirlwall J, et al. Comparison of an oral factor Xa inhibitor with low molecular weight heparin in patients with cancer with venous thromboembolism: results of a randomized trial (SELECT-D). J Clin Oncol. 2018;36(20):2017-2023.

7.McBane RD, Wysokinski WE, Le-Rademacher J, et al. Apixaban, dalteparin, in active cancer associated venous thromboembolism, the ADAM VTE Trial. Blood. 2018;132(Suppl 1):421.

8.Agnelli G, Becattini C, Meyer G, et al. Apixaban for the treatment of venous thromboembolism associated with cancer.

N Engl J Med. 2020;382(17):1599-1607.

9.Key NS, Khorana AA, Kuderer NM, et al. Venous thromboembolism prophylaxis and treatment in patients with cancer: ASCO clinical practice guideline update. J Clin Oncol. 2020;38(5):496-520.

10.Konstantinides SV, Meyer G, Becattini C, et al. 2019 ESC guidelines for the diagnosis and management of acute pulmonary embolism developed in collaboration with the European Respiratory Society (ERS). Eur Heart J. 2020;41(4):543-603.

11. Lyman GH, Carrier M, Ay C, et al. American Society of Hematology 2021 guidelines for management of venous thromboembolism: prevention and treatment in patients with cancer. Blood Adv. 2021;5(4):927-974.

12. Goto S, Haas S, Ageno W, et al. GARFIELD-VTE Investigators. Assessment of outcomes among patients with venous thromboembolism with and without chronic kidney disease. 
JAMA Netw open. 2020;3(10):e2022886.

13.Angelini DE, Radivoyevitch T, McCrae KR, Khorana AA. Bleeding incidence and risk factors among cancer patients treated with anticoagulation. Am J Hematol. 2019;94(7):780-785.

14. Trujillo-Santos J, Nieto JA, Tiberio G, et al. RIETE Registry. Predicting recurrences or major bleeding in cancer patients with venous thromboembolism. Findings from the RIETE Registry. Thromb Haemost. 2008;100(3):435-439.

15. Bauersachs R, Lee AYY, Kamphuisen PW, et al. CATCH Investigators. Renal impairment, recurrent venous thromboembolism and bleeding in cancer patients with acute venous thromboembolism-analysis of the CATCH study. Thromb Haemost. 2018;118(5):914-921.

16. Woodruff S, Feugère G, Abreu P, Heissler J, Ruiz MT, Jen F. A post hoc analysis of dalteparin versus oral anticoagulant (VKA) therapy for the prevention of recurrent venous thromboembolism (rVTE) in patients with cancer and renal impairment. J Thromb Thrombolysis. 2016;42(4):494-504.

17. Bavalia R, Middeldorp S, Weisser G, Espinola-Klein C. Treatment of venous thromboembolism in special populations with direct oral anticoagulants. Thromb Haemost. 2020;120(6):899-911.

18.van Es N, Coppens M, Schulman S, Middeldorp S, Büller HR. Direct oral anticoagulants compared with vitamin $\mathrm{K}$ antagonists for acute venous thromboembolism: evidence from phase 3 trials. Blood. 2014;124(12):1968-1975.

19.Agnelli G, Becattini C, Bauersachs R, et al. Apixaban versus Dalteparin for the treatment of acute venous thromboembolism in patients with cancer: the Caravaggio study. Thromb Haemost. 2018;118(9):1668-1678.

20.Inker LA, Astor BC, Fox CH, et al. KDOQI US commentary on the 2012 KDIGO clinical practice guideline for the evaluation and management of CKD. Am J Kidney Dis. 2014;63(5):713-735.

21. Cockcroft DW, Gault MH. Prediction of creatinine clearance from serum creatinine. Nephron. 1976;16:31-41.

22. Levey AS, Stevens LA, Schmid CH, et al. CKD-EPI (Chronic Kidney Disease Epidemiology Collaboration). A new equation to estimate glomerular filtration rate. Ann Intern Med. 2009;150(9):604-612.

23. Levey AS, Coresh J, Greene T, et al. Chronic Kidney Disease Epidemiology Collaboration. Using standardized serum creatinine values in the Modification of Diet in Renal Disease study equation for estimating glomerular filtration rate. Ann Intern Med. 2006;145(4):247-254.

24.Asar Ö, Ritchie J, Kalra PA, Diggle PJ. Joint modelling of repeated measurement and time-to-event data: an introductory tutorial. Int J Epidemiol. 2015;44(1):334-344.
25.Janus N, Launay-Vacher V, Byloos E, et al. Cancer and renal insufficiency results of the BIRMA study. $\mathrm{Br} J$ Cancer. 2010;103(12):1815-1821.

26. Prins $\mathrm{MH}$, Lensing AW, Brighton TA, et al. Oral rivaroxaban versus enoxaparin with vitamin $\mathrm{K}$ antagonist for the treatment of symptomatic venous thromboembolism in patients with cancer (EINSTEIN-DVT and EINSTEIN-PE): a pooled subgroup analysis of two randomised controlled trials. Lancet Haematol. 2014;1(01):e37-e46.

27.Agnelli G, Buller HR, Cohen A, et al. Oral apixaban for the treatment of venous thromboembolism in cancer patients: results from the AMPLIFY trial. J Thromb Haemost. 2015;13(12):2187-2191.

28. Farge D, Frere C, Connors JM, et al. International Initiative on Thrombosis and Cancer (ITAC) advisory panel. 2019 international clinical practice guidelines for the treatment and prophylaxis of venous thromboembolism in patients with cancer. Lancet Oncol. 2019;20(10):e566-e581.

29. Kearon C, Akl EA, Ornelas J, et al. Antithrombotic therapy for VTE disease: CHEST guideline and expert panel report. Chest. 2016;149(2):315-352.

30.Atiq F, van den Bemt PM, Leebeek FW, van Gelder T, Versmissen J. A systematic review on the accumulation of prophylactic dosages of low-molecular-weight heparins (LMWHs) in patients with renal insufficiency. Eur $\mathrm{J}$ Clin Pharmacol. 2015;71(8):921-929.

31.Park D, Southern W, Calvo M, et al. Treatment with dalteparin is associated with a lower risk of bleeding compared to treatment with unfractionated heparin in patients with renal insufficiency. J Gen Intern Med. 2016;31(2):182-187.

32. Verso M, Munoz A, Bauersachs R, et al. Effects of concomitant administration of anticancer agents and apixaban or dalteparin on recurrence and bleeding in patients with cancer-associated venous thromboembolism. Eur J Cancer. 2021;148:371-381.

33. Ortel TL, Neumann I, Ageno W, et al. ASH-2020 guidelines for management of venous thromboembolism: treatment of deep vein thrombosis and pulmonary embolism. Blood Adv. 2020;4(19):4693-4738.

34.McCormack T, Harrisingh MC, Horner D, Bewley S, Guideline Committee. Venous thromboembolism in adults: summary of updated NICE guidance on diagnosis, management, and thrombophilia testing. BMJ. 2020;369:m1565.

35. Hohnloser SH, Hijazi Z, Thomas L, et al. Efficacy of apixaban when compared with warfarin in relation to renal function in patients with atrial fibrillation: insights from the ARISTOTLE trial. Eur Heart J. 2012;33(22):2821-2830. 